\title{
Temperature dependent ozone absorption cross section spectra measured with the GOME-2 FM3 spectrometer and first application in satellite retrievals
}

\author{
W. Chehade, B. Gür, P. Spietz, V. Gorshelev, A. Serdyuchenko, J. P. Burrows, and M. Weber \\ Institute of Environmental Physics (IUP), University of Bremen, Bremen, Germany \\ Correspondence to: W. Chehade (chehade@iup.physik.uni-bremen.de)
}

Received: 12 August 2012 - Published in Atmos. Meas. Tech. Discuss.: 30 October 2012

Revised: 16 May 2013 - Accepted: 17 May 2013 - Published: 11 July 2013

\begin{abstract}
The Global Ozone Monitoring Experiment-2 (GOME-2) Flight Model (FM) absorption cross section spectra of ozone were measured under representative atmospheric conditions in the laboratory setup at temperatures between $203 \mathrm{~K}$ and $293 \mathrm{~K}$ in the wavelength range of $230-790 \mathrm{~nm}$ at a medium spectral resolution of 0.24 to $0.54 \mathrm{~nm}$. Since the exact ozone amounts were unknown in the gas flow system used, the measured ozone cross sections were required to be scaled to absolute cross section units using published literature data. The Hartley, Huggins and Chappuis bands were recorded simultaneously and their temperature dependence is in good agreement with previous studies (strong temperature effect in the Huggins band and weak in the Hartley and Chappuis bands). The overall agreement of the GOME-2 FM cross sections with the literature data is well within $3 \%$. The total ozone column retrieved from the GOME-2/MetOp-A satellite using the new cross section data is within $1 \%$ compared to the ozone amounts retrieved from the standard retrieval performed for GOME-2.
\end{abstract}

\section{Introduction}

The satellite borne atmospheric chemistry sensors present a powerful tool to monitor changes in the global atmospheric trace gas concentrations. Ozone $\left(\mathrm{O}_{3}\right)$ is the most important trace gas in the atmosphere (WMO, 2010; Holloway and Wayne, 2010). In the troposphere, its photolysis leads to the production of the $\mathrm{OH}$ radical which is an even stronger oxidizing agent than ozone itself. It attenuates the UV radiation in the stratosphere. Long term measurements of total ozone density and vertical profile are required to verify that the reduction in ozone depleting substances according to the Montreal Protocol resulted in the onset of recovery (WMO, 2010). Ozone absorption cross sections are essential input reference data in the retrieval of column densities and vertical distributions of atmospheric ozone and other trace gases from various platforms.

GOME-2, launched in October 2006 onboard the Meteorological Operational satellite programme (MetOp-A), measures the back scattered and reflected solar radiance at the top of the atmosphere and Earth's surface in the nadir observation mode in the $230-790 \mathrm{~nm}$ spectral range (Callies et al., 2000; Munro et al., 2006.). Total column densities of $\mathrm{O}_{3}$, $\mathrm{NO}_{2}$ and other trace gases and the vertical profile of $\mathrm{O}_{3}$ are determined from the measured data using their characteristic absorption structures (Orphal et al., 2002). Several geophysical quantities can also be inferred from GOME-2 data such as cloud parameters, surface reflectivity, and aerosol optical parameters (Munro et al., 2006.).

Two additional GOME-2 spectrometers are commissioned for the MetOp programme (MetOp-B/C); MetOp-B was launched on 17 September 2012. The GOME-2 series (MetOp programme) will provide long-term global monitoring of trace gases together with other atmospheric chemistry satellite instruments, GOME onboard ERS-2 (Burrows et al., 1999b) and SCIAMACHY onboard Envisat (Bovensmann et al., 1999). GOME and SCIAMACHY spectrometers were operated by the European Space Agency (ESA) and the GOME-2's by EUMETSAT and provided measurements from 1995 to 2011 and 2002 to 2012, respectively. They have similar optical setup for nadir viewing but differ slightly in spectral resolution. 
To obtain long-term datasets of retrieved trace gases and maintain consistency between the instruments, high-quality absorption cross section spectra are required. Using the instrument's own reference data (absorption cross section measured with the satellite spectrometer prior to its launch) in the trace gas retrieval might reduce the fit residuals and obviates the exact knowledge of the instrumental slit function or spectral resolution. For this purpose, laboratory absorption measurement of temperature dependent absorption cross sections under controlled in-flight conditions were performed in 2003 using the GOME-2 FM3 satellite instrument as a laboratory spectrometer during the general instrument calibration period (Gür et al., 2005; Gür, 2006). Similar flight model (FM) measurements of absorption cross sections were carried out with GOME (Burrows et al., 1998, 1999a) and SCIAMACHY (Bogumil et al., 2003) in the past. The ozone absorption cross section measurements with GOME, SCIAMACHY, and GOME-2 cover the entire Hartley-Huggins (UV) and Chappuis band (visible), in case of SCIAMACHY also includes the near IR Wolf bands and extends over a temperature range $\left(-70^{\circ} \mathrm{C}\right.$ to room temperature) representative for atmospheric conditions. The GOME-2 FM3 is the instrument that was launched with MetOp-A in 2006.

This paper presents GOME-2 FM3 ozone absorption cross sections measured at five temperatures $(203,223,243,273$, and $293 \mathrm{~K}$ ) in the wavelength range $230-790 \mathrm{~nm}$. The next section briefly describes the GOME- 2 spectrometer, the cross section measurements and the method used to convert to absolute absorption cross sections. Section 3 shows comparisons with published data in the different regions of the spectrum with emphasis on the total ozone retrieval spectral window $(325-335 \mathrm{~nm})$. The last section presents total ozone column retrievals from GOME-2 observations using the GOME-2 FM3 ozone cross section data.

\section{Experimental setup}

\subsection{GOME-2 spectrometer}

The GOME-2 instrument (successor of GOME) is a fourchannel grating spectrometer measuring the back scattered flux at the top of the atmosphere in the UV and visible regions and decomposes it into its spectral components. It measures continuously in the $230-790 \mathrm{~nm}$ at a spectral resolution of 0.24 to $0.53 \mathrm{~nm}$ (Full Width of Half Maximum FWHM of the Instrumental Line Shape ILS). The spectral ranges and resolutions of each channel of the GOME-2 spectrometer are listed in Table 1. A double spectrometer design with a predisperser prism and a holographic grating are used to collect the light in four cooled silicon diode array detectors (channels) each of 1024 pixels with a spectral sampling of 0.1$0.2 \mathrm{~nm}$ per pixel. The pixel exposure time (PET) is chosen independently for each channel. The GOME-2 spectrometer shows high stability and has a large dynamic range that can easily measure very small absorption from 0.001 to 2 in units of Optical Density (OD). An on-board calibration unit is included for spectral and radiometric calibration and instrument monitoring during flight. This unit contains a well isolated spectral line source (hollow cathode lamp filled with a mixture of neon and argon) and a quartz tungsten halogen lamp (White Light Source, WLS) for a broadband continuum. A detailed descriptions on the GOME-2 instrument can be found in Callies et al. (2000).

\subsection{Measurement settings and procedures}

The ozone absorption cross section measurements using the GOME-2 FM3 spectrometer were performed in a special facility at TPD/TNO in Delft (The Netherlands), where the GOME-2 spectrometer was maintained at in-flight conditions in a stabilised cryo-vaccum tank and calibrated (TPD, 2005a).

The FM campaign was conducted using the Calibration Apparatus for Trace Gas Absorption Spectroscopy (CATGAS) setup. The instrument was built by IUP/IFE at the University of Bremen and has been used in previous campaigns (Burrows et al., 1998, 1999a; Bogumil et al., 2003). The light from a stabilised high pressure Xenon lamp (Hamamatsu) traversed the absorption cell by a White type multi-path optics (White, 1942) and directed to the GOME-2 spectrometer via optical fibers. The measurements performed used a continuous flow of oxygen-ozone mixture. The gas was passed from an oxygen bottle (5.0 purity) and separated into a gas exchange unit (oxygen-ozone mixing unit) and an ozoniser where ozone was produced by an electrical discharge in pure $\mathrm{O}_{2}$. From the ozoniser, the ozone was fed to the exchange unit. The oxygen-ozone mixture branch was connected to the absorption cell. Afterwards, the gas mixture was evacuated and ozone was destroyed by a hot platinum wire. The optical path length was varied between 2.4 to $33.6 \mathrm{~m}$. Different combinations of $\mathrm{O}_{3}$ concentrations and optical path-length (mixtures) were used to cover the range of seven orders of magnitudes over which the absorption spectrum varies in the 230-790 $\mathrm{nm}$ range.

Modifications were made to the setup of previous FM campaigns to improve the stability of measurements. The pressure was controlled continuously by a pressure regulator to ensure pressure stability (better than 1\%) and continuous flow was used in all measurements by using the gas exchange unit. This helped avoiding any deformation in the vessel, optical windows or the mirrors arising from variations in the gas flow pressure. Moreover, the broadband light source was monitored during the absorption measurements by integrating a flip mirror into the optical system to correct for an effective light source drift. The modifications significantly improved baseline (background intensity without absorption) stability in the absorption measurements. A detailed description of the setup and the modifications are presented in Gür et al. (2005) and Gür (2006). 
The detector pixel exposure times of GOME-2 were optimised for each measurement such that the obtained intensity was within the linear range of the GOME-2 detector. The thermal stability during measurements was within $\pm 0.5 \mathrm{~K}$ and the accuracy of the absolute temperature values was $\pm 0.5 \mathrm{~K}$ at $293 \mathrm{~K}$ and $\pm 4 \mathrm{~K}$ at $203 \mathrm{~K}$.

The measurements with GOME-2 FM3 were conducted for each gas mixture and temperature (with constant pressure and continuous flow of oxygen) using the following sequence:

1. measurement of a reference spectrum without any ozone in the CATGAS vessel, $I_{\mathrm{ref}}\left(\lambda, t_{1}\right)$;

2. measurement of an absorption spectrum with ozone in the vessel, $I_{\text {abs }}\left(\lambda, t_{2}\right)$;

3. measurement of a second reference spectrum without ozone in the CATGAS vessel, $I_{\text {ref }}\left(\lambda, t_{3}\right)$.

Each of the above measurement steps consists of the following sub-steps: spectrum was first recorded with the light passing through the vessel ("VESSEL" spectrum). The integrated mirror was then flipped into place to project the light directly to GOME-2 spectrometer bypassing the absorption cell and the spectrum recorded ("DIRECT" spectrum). The "DIRECT" spectrum allows us to monitor the lamp source fluctuations during the entire measurement sequence (step 1 to step 3, see above).

The dark current spectrum of the detector was measured at an arbitrary time by blocking the optical path to GOME2. This spectrum was normalised to unit exposure time and could then be scaled to the exposure time selected for each measurement.

The wavelength calibration and instrument slit function were determined independently during the on-ground calibration campaign (TPD, 2005b).

\subsection{Data reduction}

All recorded spectra were corrected for dark signal by subtracting the dark current spectrum from the measured intensities. Any drift in the light source output between reference and absorption measurements appears as an additional broadband absorber in the cross section spectra. The light source drift was corrected first by calculating the ratio between the "VESSEL" and "DIRECT" spectra for each measurement. These ratios were used as the standard $\left(I\right.$ and $\left.I_{0}\right)$ intensities in the Beer-Lambert's law.

$I=I_{0} e^{-\sigma \cdot n \cdot l}$

where $n$ is the absorber concentrations and $l$ the path length through the absorber. The baseline stability (a measure for lamp drift) which is defined as the optical density calculated from the reference intensities before and after the absorption measurements, was found to be smaller than $1 \%$.
The reference intensity corresponding to the measured absorption spectrum (at time $t_{2}$ ) was then obtained by linear interpolation of the reference intensities before and after the absorption measurement as follows:

$I_{0}\left(\lambda, t_{2}\right)=\frac{t_{3}-t_{2}}{t_{3}-t_{1}} I_{0}\left(\lambda, t_{1}\right)+\frac{t_{2}-t_{1}}{t_{3}-t_{1}} I_{0}\left(\lambda, t_{3}\right)$.

From all absorption measurements, optical density spectra were calculated $\left(\mathrm{OD}=\ln \left(I_{0} / I\right)\right)$. The OD spectra measured for different mixtures at the same cell temperature were scaled to each other in overlapping regions (where matching OD spectra were both in the OD range between 0.1 and 1.0) and then concatenated to obtain the full wavelength range from 230 to $790 \mathrm{~nm}$. The scaling was obtained from linear regression fits in the overlap regions. For each of the five cell temperatures (203-293 K) a final complete OD spectrum with arbitrary measurement units was then obtained.

\subsection{Absorption cross sections}

The OD spectra are relative cross sections. The $O_{3}$ concentrations and optical path lengths $(n \cdot l$ in Eq. 1$)$ cannot be determined in the gas flow setup used here, thus the OD spectra have to be scaled to absolute cross section using published literature data: BMD (Brion et al., 1993, 1998; Malicet et al., 1995; Daumont et al., 1992) and Bass and Paur (Bass and Paur, 1985; Paur and Bass, 1985).

These literature cross sections are convenient for scaling since they also cover the temperature range at which our absorption measurements were conducted and they are available at high spectral resolution that were smoothed to GOME-2 resolution by convolving them with the GOME-2 wavelength dependent slit function (Siddans et al., 2006).

The absolute scaling of the OD spectra was performed according to the following procedure:

- The OD spectra were first placed on the correct relative temperature dependence by normalising them to unit integrated optical density of the electronic band.

- A scaling factor was determined between the five optical densities of GOME-2 spectra and the absolute cross section of the literature data at selected wavelengths from the Hartley, Huggins and the Chappuis bands.

- A single scaling factor was calculated as the weighted average of the scaling factors obtained from selected individual wavelengths.

All OD spectra were scaled at once preserving the correct temperature dependence.

\section{Temperature dependence of the cross sections}

This section presents the final GOME-2 FM3 ozone absorption cross section spectra (Fig. 1) and investigates the 


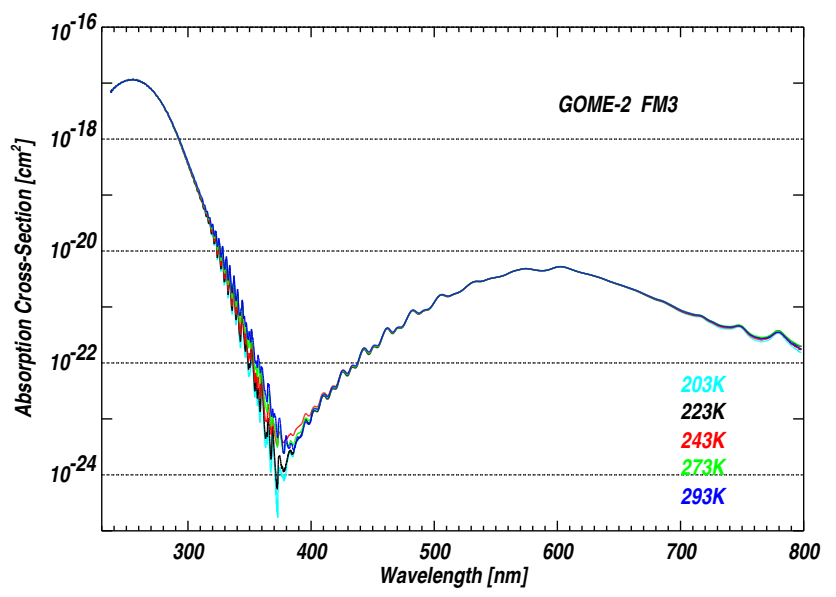

Fig. 1. Temperature dependent ozone absorption cross section spectra measured with the GOME-2 FM3 spectrometer $(230-790 \mathrm{~nm})$. The cross section cover the Hartley, Huggins and the Chappuis bands and were recorded at 203, 223, 243, 273, and $293 \mathrm{~K}$.

temperature dependence of the GOME-2 FM3 cross section spectra in the different bands by comparison to literature data. The temperature variation in the different absorption bands must also be considered in the ozone retrieval from atmospheric observations (e.g. Weber et al., 2005). The total ozone is retrieved from nadir viewing instruments in the Huggins band $(325-335 \mathrm{~nm})$ as well as the larger spectral range $275-340 \mathrm{~nm}$ for profile retrieval. The visible range of the Chappuis band $450-600 \mathrm{~nm}$ is used in DOAS (Differential Optical Absorption Spectroscopy) and SAOZ (Système d'Analyse par Observation Zénithale) measurements from the ground (Hendrick et al., 2011). The temperature dependence in the Huggins ozone band is particularly valuable to improve the determination of tropospheric ozone from profile retrieval (Chance et al., 1997). Ozone temperature dependent absorption cross sections are also required in determination of other trace gases by differential technique after subtracting the ozone contribution (Burrows et al., 1995).

\subsection{Hartley band}

The Hartley band is a strong broad continuum extending from 200 to $310 \mathrm{~nm}$ and peaks at $255 \mathrm{~nm}$ (Fig. 2). The smooth shape of the band is due to the fast photo-dissociation of ozone in the upper electronic band. Weak vibrational structures lay on top of the broadband.

In this study, the cross sections show a weak temperature effect. A slight decrease in the cross section values in the $240-260 \mathrm{~nm}$ range is observed when temperature rises. Above $260 \mathrm{~nm}$ (inversion point) the cross sections increase. The temperature variations and the inversion point were observed to be in good agreement with other laboratory measurements.

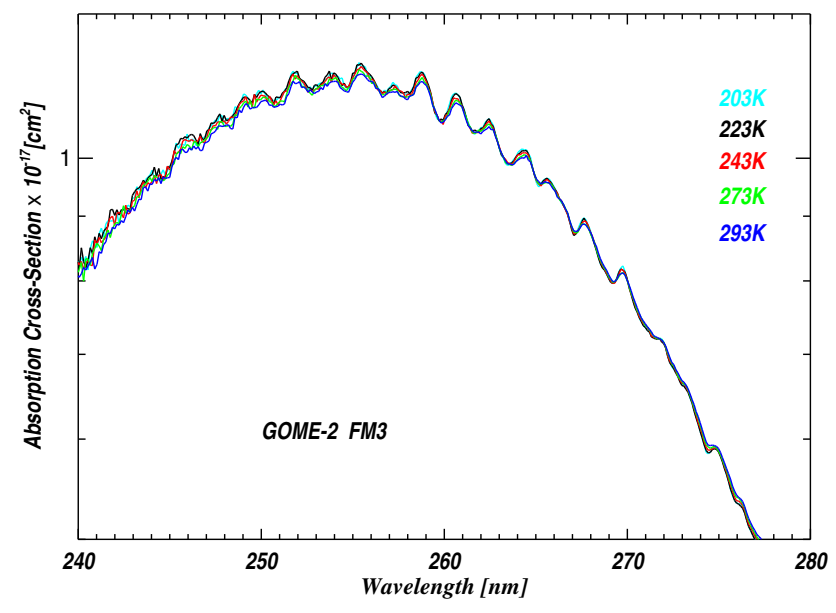

Fig. 2. GOME-2 FM3 temperature dependent absorption cross section spectra in the Hartley band.

Table 1. Spectral ranges and resolutions of each channel of the GOME-2 spectrometer.

\begin{tabular}{lll}
\hline Channels & Spectral Range & Spectral Resolution \\
\hline 1 & $240-315 \mathrm{~nm}$ & $0.24-0.29 \mathrm{~nm}$ \\
2 & $311-403 \mathrm{~nm}$ & $0.26-0.28 \mathrm{~nm}$ \\
3 & $401-600 \mathrm{~nm}$ & $0.44-0.53 \mathrm{~nm}$ \\
4 & $590-790 \mathrm{~nm}$ & $0.44-0.53 \mathrm{~nm}$ \\
\hline
\end{tabular}

At the the mercury line wavelength $(253.65 \mathrm{~nm})$, the cross sections decrease $1.5 \%$ for a temperature rise from $203 \mathrm{~K}$ to $293 \mathrm{~K}$. This variation is in good agreement with the value (1.6\%) found by Burrows et al. (1999a) and comparable to the values of about $1 \%$ reported by Molina and Molina (1986), Bass and Paur and BMD for temperature change from low temperatures (218-226 K) to room temperature.

\subsection{Huggins band}

The Huggins band $(310-380 \mathrm{~nm})$ is characterised by discrete absorption structures. The temperature effect is very strong and the cross section increases as the temperature increases. The ozone retrieval in the Huggins band from nadir viewing instruments like GOME-2 requires accurate temperature dependence of the ozone cross sections. Figure 3 shows the total ozone retrieval window between 325 and $335 \mathrm{~nm}$ (DOAS window) where strong variations in the cross section are observed specially in the region between the absorption peaks with a shift towards higher wavelengths as the temperature increase in good agreement with previous measurements. The magnitude of the variations depends on the spectral resolution of the instrument. The temperature dependence in the Huggins band is explained by changes in the rotational and vibrational distributions in the electronic ground state. 


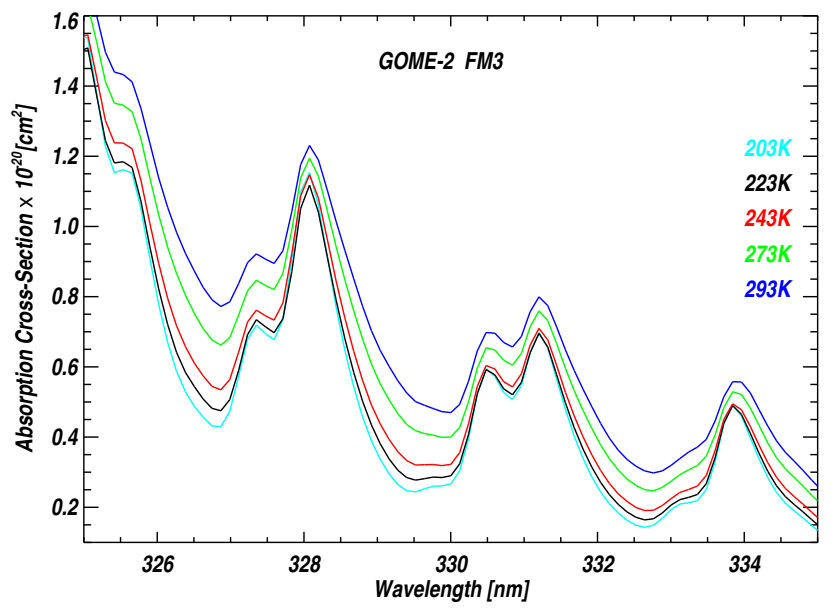

Fig. 3. GOME-2 FM3 temperature dependent absorption cross section spectra in the Huggins band. The temperature dependence is strong, the cross sections decrease with decreasing temperature.

\subsection{Chappuis band}

The Chappuis band is a broad continuum extending from 380 to $800 \mathrm{~nm}$ with vibrational structures due to the interactions of two excited electronic states. The GOME-2 FM3 data is generally in good agreement with literature data. The cross sections increase with increasing temperature below $565 \mathrm{~nm}$ and above $610 \mathrm{~nm}$ (inversions points), between the inversion points the temperature effect is the opposite (Fig. 4). At the maximum absorption peak $(602.4 \mathrm{~nm})$, an increase of $0.5 \%$ in the cross section values is observed when the temperature drops from 203 to $293 \mathrm{~K}$. This variation is in good agreement with values reported in Burkholder and Talukdar (1994) as well as Brion et al. (1998).

\section{Comparisons with literature data}

The measured absorption cross sections were compared with published literature data to assess their quality. The comparisons were performed at single wavelengths and wavelength intervals with an emphasis on the total ozone retrieval window and follow the procedures performed in the ESA study by Orphal (2002) and also summarised in Orphal (2003).

\subsection{Comparisons at Hg lamp and He-Ne laser lines at room temperature}

The FM3 data were directly compared to available literature data of absolute absorption cross sections at room temperature and at ten single wavelengths. The selected wavelengths correspond to the Hg lamp and He-Ne laser lines and are located in the Hartley and Chappuis bands where the effects of temperature, wavelength calibration and spectral resolution are weak. The results are summarised in Table 2.

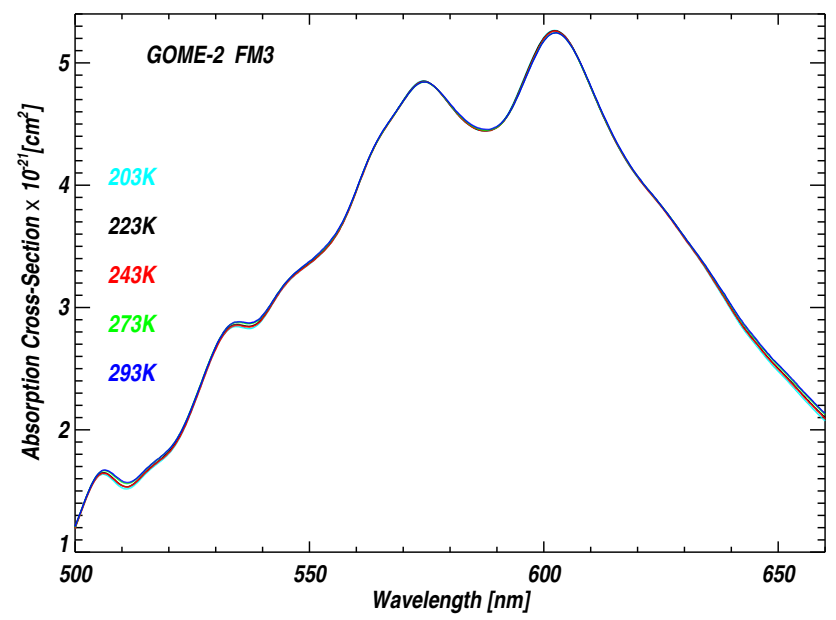

Fig. 4. GOME-2 FM3 temperature dependent absorption cross section spectra in the Chappuis band.

As shown in the table, the FM3 data at the selected wavelengths agree well with the high resolution absolute measurement data BMD and Bass and Paur as well as Burrows data. At the $\mathrm{Hg}$ line $(253.65 \mathrm{~nm})$, the mean value is $1141 \times 10^{-20} \mathrm{~cm}^{2}$ molecule and the literature values agree with each other within $2.3 \%$. The mean value is in excellent agreement with the measured GOME-2 FM3 value. The FM3 cross section values in the Chappuis band show high degree of consistency when compared to BMD and Burrows. The agreement between FM3 and Burkholder and Talukdar data is slightly worse.

\subsection{Integrated cross sections at different temperatures}

The integrated absorption cross section is insensitive to differences in wavelength calibrations and spectral resolution and, therefore can be used as a tool to evaluate the quality of the new data in the different bands. Cross sections are integrated over the regions:

- Hartley and Huggins band between 245 and 340 nm,

- Huggins band between 325 and $340 \mathrm{~nm}$,

- Chappuis band between 410 and $690 \mathrm{~nm}$,

and compared with literature data as presented in Tables 3, 4 and 5.

There is a high degree of consistency between GOME2 FM3, BMD, and Bass Paur data in the Hartley band, a weak temperature effect is observed in this band. In the Huggins band, good agreement is found with other measurements with a clear systematic temperature dependence (increase of integrated cross sections as the temperature increases). The values of the GOME-2 FM3 integrated cross section data in the Chappuis band agree very well with the mean values but they are between the values of Burrows et al. (1999a) and 
Table 2. Comparison of GOME-2 FM3 ozone cross section with literature data at ten selected wavelengths at room temperature. The absorption cross sections are given in units of $10^{-20} \mathrm{~cm}^{2}$, the second column indicates the mean from all available literature data at $298 \pm 5 \mathrm{~K}$ provided by the ESA study (Orphal, 2002).

\begin{tabular}{llrrrrrr}
\hline$\lambda[\mathrm{nm}]$ & Mean value & Bass and Paur & BMD & Molina & Burk. Tal. & Burrows & FM3 \\
\hline 253.65 & $1141 \pm 0.9 \%$ & 1145 & 1130.5 & 1157 & - & 1150 & 1141.1 \\
289.36 & $149 \pm 2.0 \%$ & 150 & 151 & 154 & - & 151 & 152.9 \\
296.73 & $60.3 \pm 1.6 \%$ & 60.7 & 61.5 & 62.3 & - & 61 & 61.4 \\
302.15 & $29.2 \pm 1.8 \%$ & 29.4 & 29.80 & 30.1 & - & 29.9 & 29.8 \\
543.52 & $0.0314 \pm 1.3 \%$ & - & 0.0312 & - & 0.0308 & 0.0317 & 0.0313 \\
576.96 & $0.0477 \pm 0.8 \%$ & - & 0.0477 & - & 0.0469 & 0.0483 & 0.0479 \\
594.10 & $0.0470 \pm 1.2 \%$ & - & 0.0468 & - & 0.0464 & 0.0476 & 0.0470 \\
604.61 & $0.0522 \pm 1.0 \%$ & - & 0.0518 & - & 0.0509 & 0.0524 & 0.0520 \\
611.97 & $0.0466 \pm 0.7 \%$ & - & 0.0463 & - & 0.0453 & 0.0469 & 0.0464 \\
632.82 & $0.0346 \pm 1.2 \%$ & - & 0.0339 & - & 0.0335 & 0.0350 & 0.0343 \\
\hline
\end{tabular}

Table 3. Comparison of integrated cross sections in the Hartley and Huggins bands $(245-340 \mathrm{~nm})$ in units of $10^{-16} \mathrm{~cm}^{2} \mathrm{~nm} \mathrm{molecule}-1$, the second column indicates the mean from all available literature (Orphal, 2002).

\begin{tabular}{llrrrr}
\hline Temperature $[\mathrm{K}]$ & Mean value & Bass and Paur & BMD & Burrows & GOME-2 FM3 \\
\hline 203 & $3.53 \pm 1.2 \%$ & 3.52 & - & 3.56 & 3.55 \\
223 & $3.53 \pm 1.1 \%$ & 3.53 & 3.50 & 3.56 & 3.55 \\
243 & $3.54 \pm 1.1 \%$ & 3.54 & 3.50 & 3.58 & 3.55 \\
273 & $3.55 \pm 1.0 \%$ & 3.54 & - & 3.58 & 3.55 \\
293 & $3.55 \pm 0.6 \%$ & 3.55 & 3.52 & 3.57 & 3.55 \\
\hline
\end{tabular}

Burkholder and Talukdar (1994) data. The weak temperature dependence (integrated cross sections increase with increasing temperature) is in good agreement with Burkholder and Talukdar but not with Burrows et al. (1999a). The Burrows et al. (1999a) ozone cross-sections (GOME FM) does not show any temperature dependence.

\subsection{Comparisons in DOAS retrieval window}

The absolute accuracy of the ozone cross section and wavelength calibration are crucial in improving the quality of the retrieved ozone amounts and reducing the ozone fit residuals. The cross sections in the Huggins band can not directly be compared due to the strong sensitivity of the data to the spectral resolution and wavelength shift. To minimise the effects of differences in wavelength calibrations, baseline drifts and spectral resolutions, a nonlinear least square fit is applied. The fitting programme employs the following parameters:

- a scaling factor to adjust the amplitude of the differential absorption structures of the cross sections (one parameter: $\left.a_{0}\right)$.

- a wavelength shift to correct for differences in the wavelength calibrations (one parameter: $a_{1}$ ).

- a cubic polynomial to account for baseline drifts (four parameters: $a_{2}$ to $a_{5}$, differential fit).
Before comparing, the literature data were smoothed to GOME-2 spectral resolution by convolving them with the wavelength dependent GOME-2 slit function (Siddans et al., 2006).

For this fitting a Marquardt-Levenberg nonlinear least squares estimation is applied to match the reference spectra $f_{\text {ref }}(\lambda)$ to the lower spectral resolution cross section spectrum $f(\lambda)$ as follows:

$f(\lambda)=a_{0} \cdot f_{\mathrm{ref}}\left(\lambda-a_{1}\right)+\sum_{i=0}^{3} a_{2+i} \cdot \lambda^{i}$

where $\lambda$ is the wavelength and $a_{i}$ are fitting coefficients.

The comparisons were made in the DOAS retrieval window (326.6-334.5 nm) at 225 and $240 \mathrm{~K}$, an example of such a fit is shown in Fig. 5. All cross sections are parameterised using the Bass-Paur temperature parameterisation (Eq. 4).

$\sigma(\lambda, T)=a_{0}(\lambda)\left[1+a_{1}(\lambda) \cdot T+a_{2}(\lambda) \cdot T^{2}\right]$

The data compared are BMD, Bass and Paur and GOME FM. GOME FM is first deconvolved with GOME slit function and the de-convolved spectra are convolved with the GOME-2 slit function.

The wavelength shifts and scaling coefficients listed in Table 6 are such that they need to be applied to the GOME FM3 cross sections in order to match the other data. A scaling factor of $+1 \%$ is expected to result in a $1 \%$ decrease in the total 
Table 4. Comparison of integrated cross sections in the Huggins band $(325-340 \mathrm{~nm})$ in units of $10^{-20} \mathrm{~cm}^{2} \mathrm{~nm} \mathrm{molecule}-1$, the second column indicates the mean from all available literature (Orphal, 2002).

\begin{tabular}{llrrrr}
\hline Temperature $[\mathrm{K}]$ & Mean value & Bass and Paur & BMD & Burrows & GOME-2 FM3 \\
\hline 203 & $5.64 \pm 3.7 \%$ & 5.44 & - & 5.93 & 5.71 \\
223 & $5.89 \pm 3.3 \%$ & 5.70 & 5.65 & 6.16 & 5.95 \\
243 & $6.30 \pm 1.8 \%$ & 6.21 & 6.23 & 6.41 & 6.37 \\
273 & $7.42 \pm 2.9 \%$ & 7.27 & 7.16 & 7.73 & 7.36 \\
293 & $8.30 \pm 0.7 \%$ & 8.20 & 8.32 & 8.35 & 8.17 \\
\hline
\end{tabular}

Table 5. Comparison of integrated cross sections in the Chappuis band (410-690 nm) in units of $10^{-19} \mathrm{~cm}^{2} \mathrm{~nm} \mathrm{molecule}-1$, the second column indicates the mean from all available literature (Orphal, 2002).

\begin{tabular}{llrrrr}
\hline Temperature [K] & Mean value & BMD & Burrows & Burkholder and Talukdar & GOME-2 FM3 \\
\hline 203 & $6.48 \pm 1.6 \%$ & - & 6.62 & - & 6.28 \\
223 & $6.35 \pm 2.4 \%$ & - & 6.55 & 6.15 & 6.30 \\
243 & $6.35 \pm 1.7 \%$ & - & 6.44 & 6.17 & 6.29 \\
273 & $6.44 \pm 2.3 \%$ & - & 6.58 & 6.20 & 6.33 \\
293 & $6.38 \pm 1.6 \%$ & 6.29 & 6.45 & 6.21 & 6.34 \\
\hline
\end{tabular}

Table 6. Direct comparison of GOME-2 FM3 with respect to literature data using a nonlinear least square fitting programme in the DOAS fitting window $(326.6-334.5 \mathrm{~nm})$.

\begin{tabular}{ccccccccc}
\hline & \multicolumn{2}{c}{ Bass and Paur } & & \multicolumn{2}{c}{ BMD } & & \multicolumn{2}{c}{ Burrows } \\
\cline { 2 - 3 } \cline { 8 - 9 } \cline { 7 - 8 } \cline { 7 - 9 } & shift & ratio & & shift & ratio & & shift & ratio \\
\hline $225 \mathrm{~K}$ & - & $2.6 \%$ & & -0.028 & $2.5 \%$ & & -0.044 & $0.0 \%$ \\
$240 \mathrm{~K}$ & 0.003 & $2.0 \%$ & & -0.028 & $2.2 \%$ & & -0.045 & $0.0 \%$ \\
\hline
\end{tabular}

column retrieval after changing the absorption cross sections. The scaling factors for GOME-2 FM3 are better than $3 \%$. To match Burrows et al. (1999a) data, the FM3 data should be shifted by $0.045 \mathrm{~nm}$, while a $2-3 \%$ scaling factor (depending on temperature) and $0.028 \mathrm{~nm}$ wavelength shift are required to match BMD and Bass and Paur data.

\section{Retrieval tests}

The total ozone retrieval is performed using the Weighting Function DOAS (WFDOAS) algorithm in the 326.6$334.5 \mathrm{~nm}$ spectral window (Coldewey-Egbers et al., 2005; Weber et al., 2005). The algorithm uses a wavelength dependent weighting function of ozone and temperature that describes the relative radiance change due to ozone column changes. The WFDOAS algorithm was successfully tested in GOME-2 data processing (Weber et al., 2007). GOME FM, convolved with the wavelength dependent GOME-2 slit function, is the reference data used currently in the GOME2 retrieval, which shows a bias of about $-1 \%$ with respect to GOME, while using BMD and Bass and Paur data lead

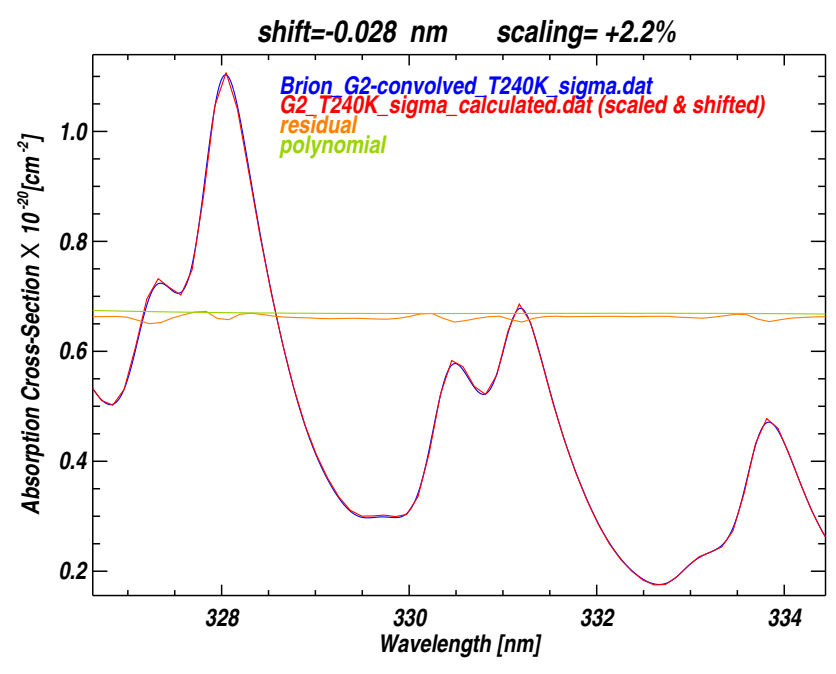

Fig. 5. Comparison of GOME-2 FM3 data with convolved BMD data at $240 \mathrm{~K}$ in the DOAS fitting window (326.6-334.5 nm). BMD data (blue) and the fitted (scaled and shifted) FM3 spectrum are shown together with the residuals (orange) and the retrieved baseline polynomial (green), the latter two vertically shifted for clarity.

to an overestimation of about 2-3\% compared to the current amounts (Weber et al., 2011).

In order to determine the cross sections at different temperatures, Bass Paur parameterisation of the temperature dependent absorption cross section data (Eq. 4) is applied to the GOME-2 FM3 cross section data. The radiation transfer code uses this parameterisation together with a temperature and ozone profile climatology to calculate the change of ozone absorption with altitude. 


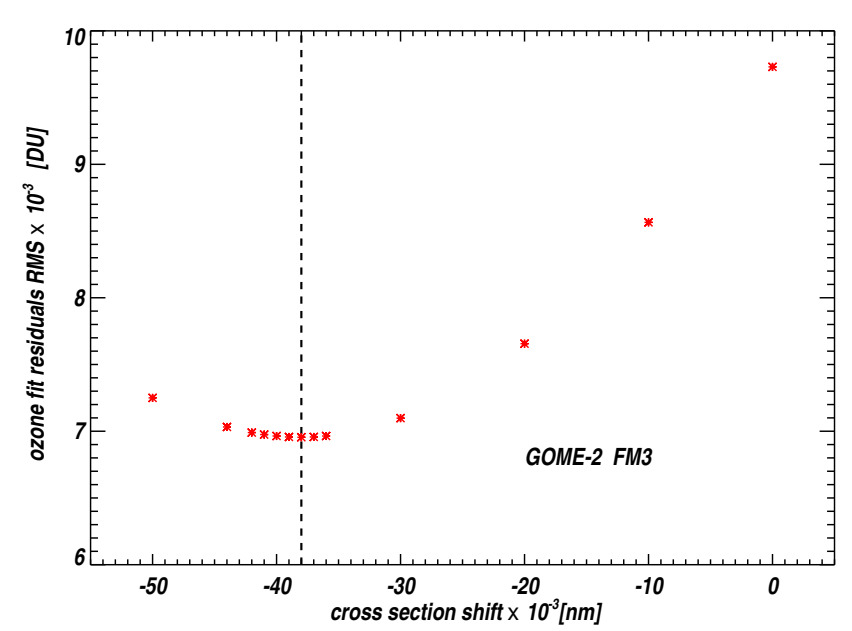

Fig. 6. GOME-2 ozone fit residuals (RMS) as a function of applied wavelength to the GOME-2 FM3 cross sections. Minimum RMS is obtained at $-0.038 \mathrm{~nm}$.

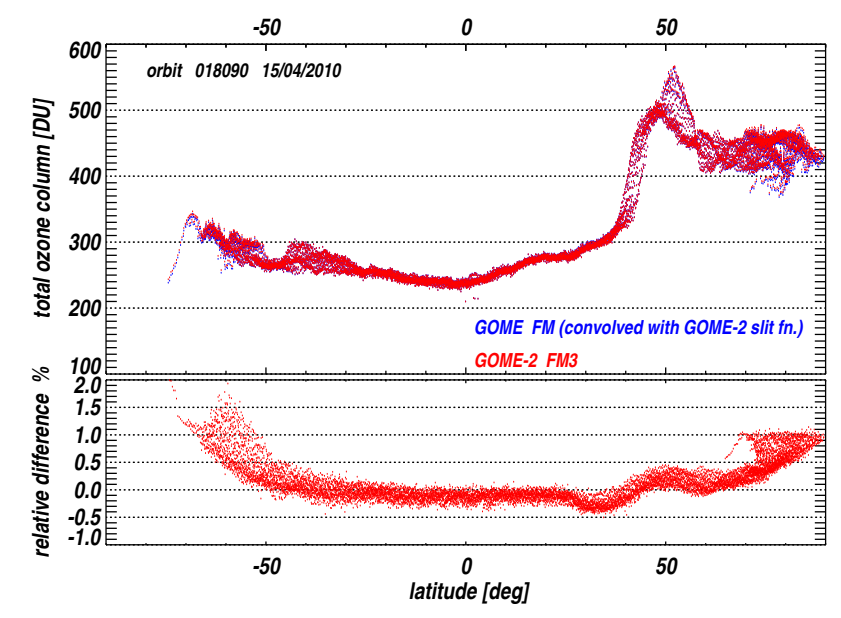

Fig. 7. GOME-2 total ozone column retrievals with different cross section data as indicated for orbit 018090 (top panel) and differences between them in percent (bottom panel).

For a detailed investigation of the new FM3 cross section data, the optimum wavelength shift applied to the cross section data in the ozone retrieval has to be found. The optimum shift, here $-0.038 \mathrm{~nm}$, minimises the ozone fit residuals (RMS) as shown in Fig. 6. Ozone fit residuals are the root-mean-square of the difference between the measured and modelled nadir radiance used in the WFDOAS algorithm. Similar shifts were obtained from the linear regression to match the BMD cross section data to GOME-2 FM3 (see above).

Figures 7 and 8 show the total ozone column (TOZ) retrieved for two selected GOME-2 orbit using different cross section data. The upper panel displays ozone columns retrieved on 15 April (orbit 018090) and 24 September 2010 (orbit 020392) using the new GOME-2 FM3 data shifted by $-0.038 \mathrm{~nm}$ (red) and GOME FM data (blue), the latter with the proper spectral resolution adjustments. The lower panels

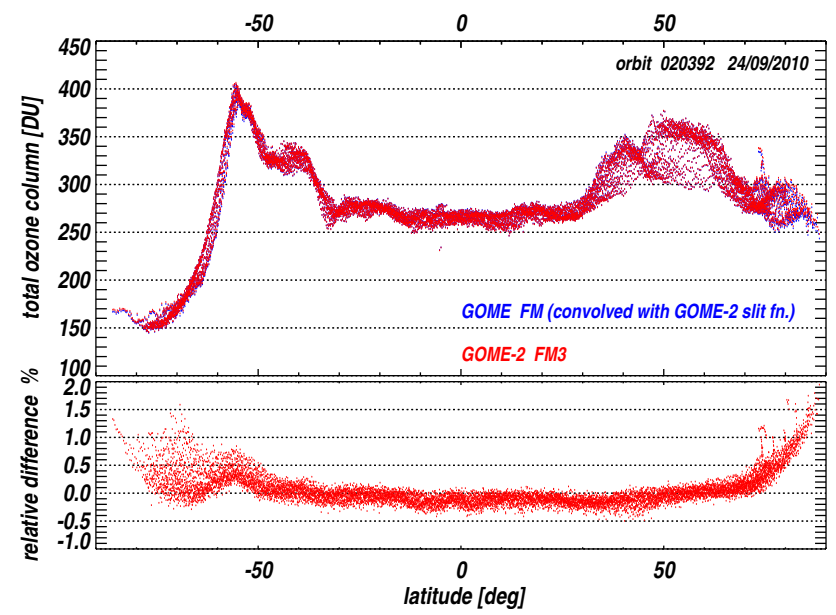

Fig. 8. GOME-2 total ozone column retrievals with different cross section data for orbit 020392 (top panel) and differences between them in percent (bottom panel).

show the relative difference between them. The relative difference is calculated as the difference between both ozone columns divided by the amounts retrieved using GOME FM (in percent). The total ozone values retrieved using the GOME- 2 FM3 cross sections is roughly $-0.5 \%$ higher compared to the total ozone currently retrieved, at higher latitudes the differences reach $+1.5 \%$, this could be probably due to differences in the temperature dependance between GOME FM and GOME-2 FM3 data. The fit residuals (RMS) are about the same.

\section{Conclusions}

The GOME-2 FM3 temperature dependent ozone absorption cross section spectra are presented in this paper. The spectra were measured at a medium spectral resolution and at temperatures between 203 and $293 \mathrm{~K}$ in the 230-790 nm spectral range. The temperature dependence of the new data is in general good agreement with literature data. Elaborate quantitative validations show a high degree of consistency between the new data and the published literature measurements, an overall agreement of $2.5 \%$ is obtained in the DOAS retrieval window after accounting for differences in the wavelength calibrations and spectral resolutions.

The total ozone column (WFDOAS) retrieved using the new reference data is close to $1 \%$ within the values currently retrieved based upon convolved GOME FM cross section data (Burrows et al., 1999a), the fit residuals are the same. The reference data obtained in this study is suitable for GOME-2 data processing and it is recommanded to use the quaratic parameterisation of the spectra to reduce the impact from a cross section spectrum at one temperature. The GOME-2 FM3 ozone cross section data are also in good 
agreement with new high spectral resolution cross section data measured in our laboratory (Serdyuchenko et al., 2011).

The new ozone cross section spectra are available on the homepage of the UV satellite data and science group of the Institute of the Environmental Physics, University of Bremen (http://www.iup.uni-bremen.de/UVSAT_material/data/ xsections/GOME-2_FM3_O3_Temp_cross-section_V5_0. txt).

Acknowledgements. The work was carried out as part of the HARMONICS project supported by the European Space Agency and, in part, supported by the State of Bremen, University of Bremen.

Edited by: A. Hofzumahaus

\section{References}

Bass, A. M. and Paur, R. J.: The Ultraviolet Cross-Sections of Ozone: Part I. The Measurements, edited by: Zerefos, S., Ghazi, A., and Reidel, D., Halkidiki Greece, Proceedings of the Quadrennial Ozone Symposium on Atmospheric Ozone, Norwell, 606-610, 1985.

Bogumil, K., Orphal, J., Homann, T., Voigt, S., Spietz, P., Fleischmann, O. C., Vogel, A., Hartmann, M., Bovensmann, H., Frerick, J., and Burrows, J. P.: Measurements of molecular absorption spectra with the SCIAMACHY pre-flight model: instrument characterisation and reference data for atmospheric remotesensing in the $230-2380 \mathrm{~nm}$ region, J. Photochem. Photobiol., A157, 157-167, 2003.

Bovensmann, H., Burrows, J. P., Buchwitz, M., Frerick, J., Noel, S., Rozanov, V. V., Chance, K. V., and Goede, A. P. H.: SCIAMACHY: Mission Objectives and Measurement Modes, J. Atmos. Sci., 56, 127-150, 1999.

Brion, J., Chakir, A., Daumont, D., Malicet, J., and Parisse, C.: High-resolution laboratory absorption cross section of $\mathrm{O}_{3}$. Temperature effect, Chem. Phys. Lett., 213, 610-612, 1993.

Brion, J., Chakir, A., Charbonnier, J., Daumont, D., Parisse, C., and Malicet, J.: Absorption spectra measurements for the ozone molecule in the 350-830 nm region, J. Atmos. Chem., 30, 291299, 1998.

Burkholder, J. B. and Talukdar, R. K.: Temperature Dependence of the Ozone Absorption Spectrum over the Wavelength Range 410 to $760 \mathrm{~nm}$, Geophys. Res. Lett., 21, 581-584, 1994.

Burrows, J. P., Holzle, E., Goede, A. P. H., Visser, H., and Fricke, W.: SCIAMACHY - Scanning Imaging Absorption Spectrometer for Atmospheric Chartography, Acta Astronaut, 35, 445-451, 1995.

Burrows, J. P., Dehn, A., Deters, B., Himmelmann, S., Richter, A., Voigt, S., and Orphal, J.: Atmospheric remote-sensing reference data from GOME: 1. Temperature-dependent absorption crosssections of $\mathrm{NO}_{2}$ in the 231-794 nm range, J. Quant. Spectrosc. Ra., 60, 1025-1031, 1998.

Burrows, J. P., Dehn, A., Deters, B., Himmelmann, S., Richter, A., Voigt, S., and Orphal, J.: Atmospheric remote-sensing reference data from GOME: 1. Temperature-dependent absorption cross- sections of $\mathrm{O}_{3}$ in the 231-794 nm range, J. Quant. Spectrosc. Ra., 60, 509-517, 1999a.

Burrows, J. P., Weber, M., Buchwitz, M., Rozanov, V. V., Ladstädter-Weissenmayer, A., Richter, A., de Beek, R., Hoogen, R., Bramstedt, K., Eichmann, K., Eisinger, E., and Perner, D.: The Global Ozone Monitoring Experiment (GOME): Mission Concept and First Scientific Results, J. Atmos. Sci., 56, 151-157, 1999b.

Callies, J., Corpaccioli, E., Eisinger, M., Hahne, A., and Lefebvre, A.: GOME-2 Metop's Second-Generation Sensor for Operational Ozone Monitoring, ESA Bull., 102, 28-36, 2000.

Chance, K. V., Burrows, J. P., Perner, D., and Schneider, W.: Satellite measurements of atmospheric ozone profiles, including tropospheric ozone, from ultraviolet/visible measurements in the nadir geometry: a potential method to retrieve tropospheric ozone, J. Quant. Spectrosc. Ra., 57, 467-476, 1997.

Coldewey-Egbers, M., Weber, M., Lamsal, L. N., de Beek, R., Buchwitz, M., and Burrows, J. P.: Total ozone retrieval from GOME UV spectral data using the weighting function DOAS approach, Atmos. Chem. Phys., 5, 1015-1025, doi:10.5194/acp5-1015-2005, 2005.

Daumont, D., Brion, J., Charbonnier, J., and Malicet, J.: Ozone UV spectroscopy I: Absorption cross-sections at room temperature, J. Atmos. Chem., 15, 145-155, 1992.

Gür, B.: Temperature Dependent Absorption Cross-Sections of $\mathrm{O}_{3}$ and $\mathrm{NO}_{2}$ in the $240-790 \mathrm{~nm}$ range determined by using the GOME-2 Satellite Spectrometers for use in Remote Sensing Applications, Ph.D. thesis, Universität Bremen, 2006.

Gür, B., Spietz, P., Orphal, J., and Burrows, J. P.: Absorption Spectra Measurements with the GOME-2 FMs using the IUP/IFE-UB's Calibration Apparatus for Trace Gas Absorption Spectroscopy CATGAS, Final Report, ESA/EUMETSAT, 2005.

Hendrick, F., Pommereau, J.-P., Goutail, F., Evans, R. D., Ionov, D., Pazmino, A., Kyrö, E., Held, G., Eriksen, P., Dorokhov, V., Gil, M., and Van Roozendael, M.: NDACC/SAOZ UV-visible total ozone measurements: improved retrieval and comparison with correlative ground-based and satellite observations, Atmos. Chem. Phys., 11, 5975-5995, doi:10.5194/acp-11-5975-2011, 2011.

Holloway, A. M. and Wayne, R. P.: Atmospheric Chemistry, ISBN:978-1-84755-807-7, Royal Society of Chemistry, Cambridge CB40WF, UK, 2010.

Malicet, J., Daumont, D., Charbonnier, J., Chakir, C., Parisse, A., and Brion, J.: Ozone UV Spectroscopy.II: Absorption cross cections and temperature dependence, J. Atmos. Chem., 21, 263 173, 1995.

Molina, L. and Molina, M.: Absolute Absorption Cross-Sections of Ozone in the 185-350 nm Wavelength Range, J. Geophys. Res., 91, 14501-14508, doi:10.1029/JD091iD13p14501, 1986.

Munro, R., Eisinger, M., Anderson, C., Callies, J., Corpaccioli, E., Lang, R., Lefebvre, A., Livschitz, Y., and Perez Albinana, A.: GOME-2 on MetOp: From in-orbit verification to routine operations, in: Proceedings of EUMETSAT Meteorological Satellite Conference, Helsinki, Finland 12-16 June 2006, 2006.

Orphal, J.: A Critical Review of the Absorption Cross-Sections of $\mathrm{O}_{3}$ and $\mathrm{NO}_{2}$ in the $240-790 \mathrm{~nm}$ Region, Part I. Ozone, ESA Technical Note MO-TN-ESA-GO-0302, 2002.

Orphal, J.: A Critical Review of the Absorption Cross-Sections of $\mathrm{O}_{3}$ and $\mathrm{NO}_{2}$ in the ultraviolet and visible, J. Photochem. Photo- 
biol., A157, 185-209, 2003.

Orphal, J., Bogumil, K., Dehn, A., Deters, B., Dreher, S., Fleischmann, O., Hartmann, M., Himmelmann, S., Homann, T., Kromminga, H., Spietz, P., Türk, A., Vogel, A., Voigt, S., and Burrows, J.: Laboratory Spectroscopy in Support of UV-Visible Remote-Sensing of the Atmosphere, in: Recent Research Developments in Physical Chemistry, 2002.

Paur, R. J. and Bass, A. M.: The Ultraviolet Cross-Sections of Ozone: Part II. Results and temperature dependence, edited by: Zerefos, S., Ghazi, A., and Reidel, D., Halkidiki Greece, Proceedings of the Quadrennial Ozone Symposium on Atmospheric Ozone, Norwell, 611-615, 1985.

Serdyuchenko, A., Gorshelev, V., Weber, M., and Burrows, J. P.: New broadband high-resolution ozone absorption cross-sections, Spectroscopy Europe, 23, 14-17, 2011.

Siddans, R., Kerridge, B., Latter, B., Smeets, J., and Otter, G.: Analysis of GOME-2 Slit function measurements, Algorithm Theoretical Basis Document, EUM/CO/04/1298/RM., 2006.

TPD: GOME-2 FM3 CALIBRATION, TPD Document number: MO-TN-TPD-GO-0060i1, Tech. Report, 2005a.

TPD: GOME-2 FM3 CALIBRATION, TPD Document number: MO-TR-TPD-GO-0097i3, Tech. Report: Wavelength Calibration and Slit Function, 2005b.

Weber, M., Lamsal, L. N., Coldewey-Egbers, M., Bramstedt, K., and Burrows, J. P.: Pole-to-pole validation of GOME WFDOAS total ozone with groundbased data, Atmos. Chem. Phys., 5, 1341-1355, doi:10.5194/acp-5-1341-2005, 2005.
Weber, M., Lamsal, N., and Burrows, J. P.: Improved SCIAMACHY WFDOAS total ozone retrieval: steps towards homogenising long-term total ozone datasets from GOME, SCIAMACHY, and GOME2, Proc. "Envisat Symposium 2007", Montreux, Switzerland, 23-27 April 2007, ESA SP-636, July 2007, available at: http://envisat.esa.int/envisatsymposium/proceedings/posters/ 3P4/463281we.pdf (last access: May 2011), 2007.

Weber, M., Chehade, W., and Spietz, P.: Impact of ozone crosssection choice on WFDOAS total ozone retrieval applied to GOME, SCIAMACHY, and GOME2 (1995-present), Contribution to ACSO (IGACO Activity: Absorption Cross-Sections for Ozone), Version 2.0, available at: http://www.iup.uni-bremen.de/ UVSAT_material/technotes/weber_acso_201101.pdf (last access: May 2011), Universität Bremen, Bremen, 2011.

White, J.: Long Optical Paths of Large Aperture, J. Opt. Soc. Am., 32, 285-288, 1942.

WMO: World Meteorological Organization: Global Ozone Research and Monitoring Project, Scientific Assessment of Ozone Depletion: 2010, Report No. 52, World Meteorological Organization, Geneva, 2010. 